\title{
Student Motivation and Interests as Proxies for Forming STEM Identities
}

\author{
Todd Campbell $\cdot$ Hyonyong Lee ${ }^{1 *} \cdot$ Hyuksoo Kwon $\cdot$ Kyungsuk Park ${ }^{1}$ \\ Utah State University $\cdot{ }^{1}$ Kyungpook National University
}

\begin{abstract}
This research investigated the motivation and interests of a sample of predominately-underrepresented populations to better understand whether informal STEM learning experiences offer support for developing STEM identities. A valid and reliable three-section self-reporting survey was administered to 169 secondary students as the primary data source. Identity was used as a theoretical lens along with descriptive statistics to reveal students' perceived benefits of the informal STEM learning experience, a Mathematics, Engineering, Science Achievement (MESA) program in the western U.S., for improving their understanding of science, mathematics, and engineering concepts, increasing their interest in science, mathematics, and engineering careers, and increasing their belief of the importance of these STEM disciplines. In summary, the findings emerging, considered alongside current identity research, suggest that informal STEM learning experiences offer students from underrepresented STEM populations the space needed for successful STEM identity bids, either for future career pursuits or participation in a STEM literate populace as a non-STEM professional societal member.
\end{abstract}

Key words: STEM education, Informal STEM learning, MESA, Motivation, Interest, STEM identity

\section{Introduction}

Science, technology, engineering, and mathematics (STEM) areas are enjoying widespread attention in both public policy discussions and funding allocations (e.g. U.S. Government Accountability Office, 2005). This recent increased attention for STEM areas has emerged in part because of future national and international requisite needs in STEM areas. As an example, great concern has arisen in the U.S. over "not preparing a sufficient number of students, teachers, and practitioners in the areas of science, technology, engineering, and mathematics (STEM)" (Kuenza, 2008, p. 1). Data drawn on specifically in the U.S. to support these claims are found in lagging national and international student assessments, such as the National Assessment of Education Progress (NAEP), Trends in International Mathematics and Science Study (TIMSS), and the Program for International Student Assessment (PISA). In addition to STEM concerns based on claims of inadequate preparation, additional important concerns arise when considering the achievement and representation of diverse populations within STEM areas. In the U.S. these concerns are substantiated as dismal numbers of underrepresented populations (Black, Latino, and American Indian) are graduating from high school in the U.S. in comparison to White and Asian students, approximately 60\% compared to 80-90\% respectively (Education Trust, 2009). Additionally, these concerns are substantiated as the numbers of underrepresented populations in science careers are examined (e.g. only $0.4 \%$ of $\mathrm{Ph} . \mathrm{D}$. practicing scientists are Black Women according to NSF, 2008).

While a strong case can be made for increasing focus on STEM areas based on concerns for competitiveness, a MORE important and allencompassing case can be made for increasing the focus on STEM areas so that national and international societies are governed and informed by STEM literate populaces. These informed STEM literate populaces are made up of sufficient numbers of STEM professionals, but

\footnotetext{
*Corresponding author: Hyonyong Lee (hlee@knu.ac.kr)

** Received on 19 March 2012, Accepted on 10 April 2012

***This research was supported by Kyungpook National University Research Fund, 2009.
} 
are also envisioned with non-STEM professionals (e.g. artists, politicians, journalists), the rest of the population, also having developed STEM identities capable of understanding and 'weighing in' on STEM matters important for future global and national well-being.

While attention is needed within the formal education system to ensure that an informed STEM literate populace is developed, research is emerging to suggest that informal STEM learning opportunities are as important to consider, especially for underrepresented populations (Aschbacher et al., 2010; Stake \& Nikens, 2005). Some of the most compelling research demonstrating the promise of informal STEM learning opportunities is related to identity development (Johnson et al., 2011) and specifically considers identity "bids for recognition' (Gee 2000-2001), or the agency that learners either have or do not have as they consider themselves inside or connected to STEM careers or STEM thinking and discourse. To learn more about increasing the numbers of underrepresented populations in STEM, this current research investigates the motivations and interests as students engage in informal science learning experiences using the lens of identity. The following are the research questions that guided this study:

- What aspects of the informal STEM learning opportunities, specifically the MESA program, influence students' interests and motivations related to attitudes about STEM?

- What can be learned about informal STEM learning opportunities with respect to identity development for underrepresented populations?

\section{Literature Situating this Research}

Identity. Identity is defined for the purposes of this research as the sense of who students are, what they believe they are capable of, and what they want to do or become (Brickhouse,
2001). Like many other researchers investigating identity with underrepresented populations (Aschbacher et al., 2010; Carlone \& Johnson, 2007; Malone \& Barabino, 2009), this research is informed by both situated learning theory (Lave \& Wenger, 1991) whereby learning is seen as taking place through social interactions within 'communities of practice', as well as agency which considers whether underrepresented populations who typically have not authored identities or made successful bids for identity within fields such as STEM are able to do so based on their specific individual actions.

So, as Aschbacher et al. (2010) share, STEM areas do have "common languages, conventions, rituals, stories, and histories valued in each community" (p. 565) and forming an identity in or shaped by a STEM areas necessitates at least some integration of these commonalities into students' sense of who they are. But, as Gee (2000-2001) and Johnson et al.(2011) point out, agency to engender a STEM identity is socially influenced as some bids are accepted by those individuals making them, while others fail, sometimes because of the social pressures surrounding them. In Johnson et al.(2011) specifically, they suggest that within agency, one must also consider what they referred to, specifically for women of color bidding for identities as scientists in their research, as a matrix of oppression. These types of matrices counteract agency at times, so that bids are more likely to be unsuccessful. Many see these matrices of oppression as social pressures that go against successful STEM identity bids, but some interventions have been suggested for overcoming resistance to successful STEM identity bids. Among these are the informal STEM learning opportunities that are described next.

\section{Informal STEM Learning Opportunities.} Informal learning opportunities are described as any STEM learning opportunities that occur outside of the formal classroom instructional time. One example of this type of opportunities might 
come as a group of Latino females, an underrepresented population in STEM areas in the U.S., work closely with an engineer over several months after school to co-design a windmill for an upcoming challenge. Recent identity research suggests that these types of experiences are instrumental in fostering identities, especially since they position students in climates where successful bids are more likely to be fostered to develop common capital within STEM areas (e.g. common language, practices). These experiences also offer a safe environment with others who are also from underrepresented populations (Aschbacher et al., 2010). The MESA program introduced and investigated in this research is an example of one such informal STEM learning opportunity found in the Western U.S.

Mathematics, Engineering, Science Achievement (MESA) Program and Competitions. Mathematics, Engineering, Science Achievement (MESA) is one successful and longstanding STEM education program. The MESA outreach program has been administered through the California Public School System in the U.S. since 1970. California MESA received the U.S. Presidential Award for Excellence in Science, Mathematics and Engineering Mentoring in 2000. Because of the success of the MESA program in California, the program has expanded to seven other states. MESA USA is a partnership of MESA programs in eight U.S. states: Arizona, California, Colorado, Maryland, New Mexico, Oregon, Utah, and Washington. MESA USA programs include many of the following elements: study skills training, hands-on activities, competitions, career and college exploration through field trips and guest speakers, parent leadership development and so on. Annually, students in MESA USA programs participate in local and national engineering design competitions.

Despite many efforts to scale up the MESA program, there is very little research that investigates students' perceptions and motivation as they relate to the program and more broadly how engaging in the MESA program, as an example of informal learning opportunities, can influence student identity development. This study is designed to meet this need as an initial investigation into the impacts of the features of the MESA programs.

\section{Methods}

Participants and Context. The participants of the study were all from Utah in the Western U.S. in the 2010 MESA program. All participants selected for this study attended the 2010 MESA Wind Energy Challenge, a statewide competition held at a theme park in central Utah. In the MESA Wind Energy Challenge students engaged in the following competitions: authoring a technical paper, preparing an academic display, presenting an oral presentation, and demonstrating the performance of a constructed device for harnessing wind energy to produce electricity and move masses. All participants engaged in the MESA Wind Energy Challenge and varying other aspects of the MESA program. In summary, the 179 secondary students who participated in the 2010 Utah MESA Wind Energy Challenge were invited to participate in this study. Because the MESA Wind Energy Challenge was seen as an informal STEM learning opportunity with increased numbers of underrepresented populations, it was seen as a fitting context for this research.

Instrument. A self-reporting student survey consisting of three sections was used as the primary data source for this research. The following gives more details about each of these three sections: Demographics-the demographic section of the survey consisted of eight items for gathering the following information: gender, school year, ethnicity, grade point average (GPA), future career, favorite subject, MESA participation year(s), and number of MESA activities. Most of the items were multiplechoice items (e.g. What is your gender?), but two 
of the items were open response items (e.g. What future career are you interested in at this time?).

Participants' perceived benefits of the MESA program - Items in this section where intended to gather information about students' perceived benefits of the MESA program. This section consisted of six items - three multiple choice and three open-ended response items.

Participants' attitudes associated with the MESA programs and competitions-This section focused on student attitudes as they related to understanding STEM areas and STEM related careers based on experiences more generally in MESA programs and more specifically in MESA competitions. Attitudes related to understanding STEM areas were gathered using 12 items where students were presented with statements such as 'MESA programs help me understand science concepts and skills I learn in school and asked to identify their level of agreement on a fivepoint Likert-type scale from 5-Completely Agree to 1-Completely Disagree.

Content Validity. The entire three-section self-reporting student survey was reviewed for content validity by a panel of experts made up of STEM education and educational research/ measurement scholars who hold doctorates in one field of STEM education. After an introduction to the research project and purposes of this study, the experts provided feedback for individual items of the instrument. Based on the suggestions and comments, the instrument was revised and finalized.

Reliability of Constructs. Only the Participants' attitudes associated with the MESA programs and competitions section of the survey contained enough items to determine the reliabilities of the internal constructs. Given this, within section three the reliabilities (Cronbach alphas) of students' perceived benefits of the MESA program (STEM learning related to the MESA program and STEM career preferences related to the MESA program,) and students' perceived benefits of MESA competitions (STEM importance related to the MESA competitions and STEM learning related to the MESA competitions) were measured at 0.732, 0.790, 0.739 , and 0.816 respectively. Based on these acceptable reliabilities, as well as the established construct validity as judged by the expert reviewers, it was believed that this instrument was an acceptable measure for providing insight on the research questions.

Data Collection. Students who participated in the 2010 MESA Wind Energy Challenge were asked to complete the MESA Questionnaire for Students. Of the 179 participants, 169 participants responded, which is a total response rate of $94 \%$.

Data Analysis. Because data was only collected during the competition, only descriptive statistics were computed to answer the research questions.

\section{Results and Discussion}

Demographic Information. A total of 169 respondents (46.2\% male and $53.8 \%$ female students) completed the survey instrument. The majority of respondents ( $\mathrm{n}=123,72.6 \%)$ were non-Caucasian students such as Hispanic or Latino (34.5\%), Asian (24.4\%), and others (13.7\%). There was a relatively balanced distribution of school grades ( $7^{\text {th }}$ grade: $20.7 \%$, 8th grade: $5.3 \%$, $9^{\text {th }}$ grade: $19.5 \%, 10^{\text {th }}$ grade: $21.9 \%, 11^{\text {th }}$ grade: $18.3 \%$, and $12^{\text {th }}$ grade: $14.2 \%$ ). In addition, about half $(46.2 \%)$ of the respondents $(n=78)$ reported a high GPA (4.0-3.5) in their school work. Approximately half $(52.7 \%)$ of the respondents reported participating in the MESA program for one year. Other smaller groups reported participating for multiple years (i.e. two years participation $(27.2 \%)$, three years participation (14.2\%), and others (5.9\%). Additionally, $61.5 \%$ of the respondents reported participating in one- 
to-five MESA activities.

Based on these demographics, it can be seen that most participants in MESA are from underrepresented groups. It can also be seen that to some extent, based on the reported GPAs as an example (i.e. approximately 50\% with GPAs between 3.5-4.0), many of these student have already begun successful identity bids in STEM areas in formal STEM learning contexts. It seems timely here to mention research findings suggesting that interest in STEM careers is not something that perhaps has to be developed as much as it may just need support for sustaining. As an example, Aschbacher, Li, and Roth (2010) found that for the most part, interests in science as a representative STEM area was already present for the 33 high school participants in their study, stating that "[n]o students were found who developed a new strong interest in science after $10^{\text {th }}$ grade" ( $p$. 569). Instead they found that more important was the need to foster student interests and cultivate identities by increasing students' experiences and capital in science areas. So, an initial look at the demographics of the population investigated here reveals findings emerging elsewhere, and further supports the need for programs such as MESA.

Participants' perceived benefits of the MESA program. The study investigated the students' perceived benefits of the MESA program by asking them to answer questions like: "Do you think the MESA programs help you improve your study?" or "If you answered yes to the previous question, which subjects are improved after MESA program experiences?" Most of the respondents $(87 \%, \mathrm{n}=147)$ reported that they felt the MESA program improved their academic performance in school. Beyond that, from those reporting a positive impact of the MESA program $(n=147)$, Table 1 reveals the specific school subjects they believed were improved.

As can be seen in Table 1, a significant number

\section{Table 1}

Subjects that participants felt were improved as a result of MESA programs

\begin{tabular}{lcc}
\hline \multicolumn{1}{c}{ Subjects } & Frequency & Percentage \\
\hline Science & 30 & 20.4 \\
Technology & 4 & 2.7 \\
Engineering & 21 & 14.3 \\
Mathematics & 32 & 21.8 \\
Others & 59 & 40.8 \\
\hline
\end{tabular}

of students felt that the MESA program improved their academic performance in science, engineering, and mathematics. Additionally, because the question prompting students to identify which academic areas were improved was open-ended, many students reported an improvement in multiple STEM areas. When this occurred, the responses were reported in Table 1 as 'other' (e.g. if a student reported improvement in science and mathematics).

Another part of the Participants' perceived benefits through of the MESA program section of the survey asked participants to identify which specific MESA activities within the MESA program they liked best. Data collected about participants' favorite MESA activities is found in Table 2.

According to the participant responses, the most preferred MESA activities were hands-on activities (45\%, $n=76)$, participating in the MESA competitions $(21.3 \%, \mathrm{n}=36)$, and experiencing career and college exploration field trips (17.2\%, $\mathrm{n}=29)$. Aschbacher, Li, and Roth (2010) shared in their research investigating identity development in science for underrepresented students:

School science was often hard and discouraging; there were very few science advocates at school or home; and meaningful opportunities to work with real science professionals were scarce... Students expressed positive attitudes toward science and non-science pursuits where 


\section{Table 2}

Students' Favorite MESA Activities

\begin{tabular}{|c|c|c|}
\hline MESA Activities & Frequency & Percentage \\
\hline Career \& College Exploration Field Trips & 29 & 17.2 \\
\hline Guest Speakers & 7 & 4.1 \\
\hline Competitions & 36 & 21.3 \\
\hline Hands-on Activities & 76 & 45.0 \\
\hline Student Advisement & 3 & 1.7 \\
\hline Study Skills Training & 3 & 1.7 \\
\hline Other-Mathematics + Physics & 5 & 3.0 \\
\hline All & 2 & 1.2 \\
\hline Other Combinations & 8 & 4.8 \\
\hline Total & 169 & 100.0 \\
\hline
\end{tabular}

they experienced success and received support ... results underscore the key role communities of practice play in career and identity development.... (p. 564).

Based on the findings emerging and the understanding that MESA programs include opportunities to work with real scientists and support for STEM learning, the MESA program seems to be enhancing the possibility of successful STEM identity bids even when school science is 'hard'. Additionally, the ways in which MESA seems to be resonating most with students are through offering hands-on activities and college and career exploration opportunities. These activities also seem capable of supporting students' agency in forming STEM identities as they help these underrepresented students resist 'structural constraints' situated within any matrices of oppression that have excluded these populations from STEM identities in the past (Johnson et al., 2011).

Participants' attitudes associated with the MESA program and competitions. Finally, participant attitudes as they related to STEM learning and STEM careers connected to the MESA program generally and the MESA competitions more specifically were investigated.
Twelve items separated into four different constructs were developed and explored. The findings for these constructs are found in Table 3.

Table 3 presents the means and standard deviations for the twelve survey items. Based on these means on a 1-5 scale with 5 being the most positive (i.e. Completely Agree), it is apparent that both the MESA program and competitions positively impacted students' STEM learning, their understanding of the importance of STEM, and their attitudes toward pursuing STEM careers.

The data from this final section of the survey was also analyzed to consider whether correlations could be found between selfreported increased understanding of STEM subjects and increased preference for specific STEM careers (e.g. scientist, engineer). The correlations for this investigation are found in Table 4.

As can be seen in Table 4, significant correlations were found for all areas of learning (e.g. reported increases in science learning correlated with increases in mathematics learning). Similarly, significant correlations were found between increased STEM learning in mathematics and science related to MESA and career preferences in science, mathematics, and engineering. Additionally, significant correlations 
538

Todd Campbell $\cdot$ Hyonyong Lee $\cdot$ Hyuksoo Kwon $\cdot$ Kyungsuk Park

Table 3

Students' Perceived Benefits of the MESA Programs and Competitions

\begin{tabular}{|c|c|c|c|}
\hline \multirow{2}{*}{$\begin{array}{l}\text { Items } \\
\text { MESA Program \& STEM Learning } \\
1 \text {. Help me understand science concepts and } \\
\text { skills I learn in School }\end{array}$} & $\mathrm{N}$ & Means & S.D. \\
\hline & 169 & 4.20 & .78 \\
\hline $\begin{array}{l}\text { 2. Help me understand math concepts and } \\
\text { skills I learn in School }\end{array}$ & 169 & 4.14 & .88 \\
\hline $\begin{array}{l}\text { 3. Help me understand engineering concepts } \\
\text { and their application }\end{array}$ & 169 & 4.33 & .92 \\
\hline $\begin{array}{l}\text { MESA Program \& Career Preference } \\
4 . \quad \quad \text { Made me think about becoming a scientist }\end{array}$ & 169 & 3.44 & 1.25 \\
\hline $\begin{array}{l}5 . \quad \text { Made me think about becoming a } \\
\text { mathematician }\end{array}$ & 169 & 3.24 & 1.26 \\
\hline Made me think about becoming an engineer & 169 & 3.52 & 1.31 \\
\hline $\begin{array}{l}\text { MESA Competitions \& STEM importance } \\
7 . \quad \text { Help me understand the importance of } \\
\text { science }\end{array}$ & 169 & 4.11 & .86 \\
\hline $\begin{array}{l}\text { 8. Help me understand the importance of } \\
\text { mathematics }\end{array}$ & 169 & 4.04 & .99 \\
\hline $\begin{array}{l}\text { 9. Help me understand the importance of } \\
\text { engineering }\end{array}$ & 169 & 4.20 & .90 \\
\hline $\begin{array}{l}\text { MESA Competitions \& STEM Learning } \\
10 . \quad \text { I have learned a lot about science }\end{array}$ & 169 & 3.91 & 1.01 \\
\hline 11. $\quad$ I have learned a lot about math & 169 & 3.79 & 1.10 \\
\hline I have learned a lot about engineering & 169 & 4.09 & .92 \\
\hline
\end{tabular}

Table 4

Correlations between increases in STEM learning and preferences for STEM Careers

\begin{tabular}{lccccc}
\hline \multicolumn{1}{c}{ Items } & 1 & 2 & 3 & 4 & 5 \\
\hline 1. Learning Science Concept and Skills & - & & & & \\
2. Learning Math Concepts and Skills & $.642^{* *}$ & - & & & \\
3. Learning Engineering Concepts and Skills & $.429^{* *}$ & $.388^{* *}$ & - & & \\
4. Becoming a Scientist & $.350^{* *}$ & $.224^{* *}$ & .141 & - & \\
5. Becoming a Mathematician & $.243^{* *}$ & $.345^{* *}$ & .089 & $.587^{* *}$ & - \\
6. Becoming an Engineer & $.266^{* *}$ & $.208^{* *}$ & $.279^{* *}$ & $.577^{* *}$ & $.507^{* *}$ \\
\hline
\end{tabular}

** $\mathrm{p}<.01$

were also found with respect to participant interest in STEM careers, more specifically, as an example, an increased interest in being a scientist also correlated with an increased interest in being an engineer. Finally, an interesting finding emerged with respect to learning engineering concepts and skills as these were not found to be significantly correlated with interests in careers in science and mathematics.

In terms of STEM identity, findings from this section of the survey support the MESA program and competitions as examples of informal STEM learning opportunities which can play an 
important role in fostering students' interest in pursuing STEM careers, while at the same time supporting them to navigate any social pressures that may come against them.

One interesting finding emerging from this section of the survey relates to the absence of correlation between learning engineering concepts and skills and interest in mathematics and science careers. While no data was gathered to better understand this during this study, these findings in the U.S. may perhaps be indicative of the lack of engineering design within mathematics and science curricula currently. Most recently, NRC(2012) released A Framework for $K-12$ Science Education: Practices, Crosscutting Concepts, and Core Ideas that did include a new focus on engineering design, but this is not something that has been central in either mathematics or science classes, so it makes sense initially that students are not connecting learning engineering concepts and skills with interests in careers in science and mathematics.

\section{Summary and Conclusion}

This study set out to better understand the aspects of the informal STEM learning opportunities that influence students' interests and motivations about STEM. The findings revealed that students felt that the informal STEM learning opportunities associated with programs like MESA not only increase their capacities in STEM disciplines, they also contribute to their consideration of pursuing STEM careers. In addition, students reported strongest preferences toward 'hands-on' activities and college and career exploration field trips. Based on notions about identity development, these findings suggest that MESA programs, as representative informal STEM learning opportunities, provide the space, mentoring, and support reported necessary for successful STEM identity bids.

This research also sought to better understand what role informal STEM learning opportunities might play with respect to identity development for underrepresented populations. Other researchers have documented essential components of identity development for underrepresented populations. One essential component highlighted is informal STEM learning experiences whereby space is provided for successful bid establishment in the company of other underrepresented students. Another essential component involves some level of enculturation into STEM communities of practice, so that underrepresented students can better navigate the treacherous obstacles of school science that do not necessarily always focus on engaging students in doing science, but instead in many instances are steeped in structures that 'weed out' those without the community of practice languages, conventions, rituals and histories. Evidence of MESA programs and competitions providing these types of essential identity support can be found as students reported connections between developing skills in content areas and school subject academic achievement, in addition to attributing career considerations in STEM areas to experiences in the MESA program and competitions.

This research, specifically designed to consider underrepresented student STEM identity development, provides evidence supportive of the importance of informal STEM learning opportunities. As more and more attention is placed on STEM areas nationally in the U.S. or internationally, considerations such as those made here will be needed with increased attention both to formal STEM learning experiences (e.g. continuing to consider the role of engineering design in secondary education among other areas so that students consider engineering bids that were not noted in this particular research) and informal STEM learning opportunities like the MESA programs and competitions. 


\section{References}

Aschbacher, P. R., Li, E. \& Roth, E. J. (2010). Is science me? High school students' identities, participation, and aspirations in science, engineering, and medicine. Journal of Research in Science Teaching, 47(5), 564-582.

Brickhouse, N. W. (2001). Embodying science: A feminist perspective on learning. Journal of Research in Science Teaching, 38(3), 282295.

Carlone, H. B., \& Johnson, A. (2007). Understanding the science experiences of successful women of color: Science identity as an analytic lens. Journal of Research in Science Teaching, 44(8), 1187-1218.

Education Trust. (2009). Education watch national report. Washington, DC: Education Trust.

Gee, J. P. (2000-2001). Identity as an analytic lens for research in education. Review of Research in Education, 25, 99-125.

Johnson, A., Brown, J., Carlone, H. \& Cuevas, A.K. (2011). Authoring identity amidst the treacherous terrain of science: A multiracial feminist examination of the journeys of three women of color in science. Journal of Research in Science Teaching, 48(4), 339-366.

Kuenzi, Jeffrey J. (2008). Science, Technology, Engineering, and Mathematics
(STEM) Education: Background, Federal Policy, and Legislative Action. Congressional Research Service Reports. Paper 35. http://digitalcommons. unl.edu/crsdocs/35

Lave, J., \& Wenger, E. (1991). Situated learning: Legitimate peripheral participation. Cambridge: Cambridge University Press.

Malone, K., \& Barabino, G. (2009). Narrations of race in STEM research settings: Identity formation and its discontents. Science Education, 93(3), 485-510.

National Research Council (2012). A Framework for K-12 Science Education: Practices, Crosscutting Concepts, and Core Ideas. Washington, DC: The National Academies Press.

NSF. (2008). Women, minorities, and persons with disabilities in science and engineering: U.S. demographics (December 2008 ed.). National Science Foundation.

Stake, J. E., \& Nikens, S.D. (2005). Adolescent girls' and boys' science peer relationships and perceptions of the possible self as scientist. Sex Roles, 52(1/2), 1-11.

U.S. Government Accountability Office (2005), Federal Science, Technology, Engineering, and Mathematics Programs and Related Trends, GAO-06-114. 